\title{
PENGARUH PERSEPSI KERJA DAN MOTIVASI KERJA TERHADAP KINERJA DOSEN SEKOLAH TINGGI PARIWISATA AMPTA YOGYAKARTA DENGAN KOMPENSASI KERJA SEBAGAI VARIABLE MODERASI.
}

\author{
Parsidi dan Soetomo WE. Hendrajaya \\ Dosen Sekolah Tinggi Pariwisata AMPTA Yogyakarta
}

\begin{abstract}
The title of this research is The Influence of Work Perception and Work Motivation on the Lecturers's Performances in Sekolah Tinggi Pariwisata AMPTA Yogyakarta with Compensation as the moderating variable. This research aims to investigate the influence of Work Perception, Work Motivation on the Lecturers' performances in Sekolah Tinggi Pariwisata AMPTA Yogyakarta with Compensation as the moderating variable.

The research was an Inferential Quantitative. The sample consist of 39 persons who were permanent Lecturers in Sekolah Tinggi Pariwisata AMPTA. The sample was established by applying Census sampling method because the respondent were less than 100 persons. The data were collected by using questionnaire. The data were tested and analyzed by applying multiple linear regression.

The analysis results indicated that (1) work perception positively influencing and significant to the lecturers performances, (2) work motivation positively influencing and significant to the lecturers' performances, (3) work compensation positively influencing and significant to the lecturer' performance, (4) work perception positively influencing and significant to the lecturers' performance with work compensation as moderating variable, and (5) work motivation positively influencing and significant to the lecturers'performance with work compensation as moderating variable.
\end{abstract}

Keywords: Work perception, Work motivation, Lecturers 'performances, work Compensation.

\section{PENDAHULUAN.}

Pendidikan merupakan salah satu upaya yang sangat penting dalam meningkatkan kualitas sumber daya manusia. Dengan meningkatnya kualitas sumber daya manusia pada suatu bangsa, maka bangsa tersebut akan semakin berkembang dan maju. Sebagaimana yang diamanatkan dalam Undang-undang No. 12 tahun 2012 tentang Pendidikan tinggi ditegaskan bahwa bahwa pendidikan tinggi sebagai bagian dari sistem pendidikan nasional memiliki peran strategis dalam mencerdaskan kehidupan bangsa dan memajukan ilmu pengetahuan dan teknologi dengan memperhatikan dan menerapkan nilai humaniora serta pembudayaan dan pemberdayaan bangsa Indonesia yang berkelanjutan.
Berdasarkan Undang-undang No. 12 Tahun 2012 Pendidikan tinggi berfungsi sebagai berikut :

1. Mengembangkan kemampuan dan membentuk watak serta peradaban bangsa yang bermartabat dalam rangka mencerdaskan kehidupan bangsa;

2. Mengembangkan Sivitas Akademika yang inovatif, responsif, kreatif, terampil, berdaya saing, dan kooperatif melalui pelaksanaan Tridharma; dan

3. Mengembangkan Ilmu Pengetahuan dan Teknologi dengan memper-hatikan dan menerapkan nilai Humaniora.

Tugas dan tanggung jawab dosen di jelaskan pada pasal 12 ayat 1 (satu) yang berbunyi dosen sebagai anggota sivitas akademika memiliki tugas 
mentransformasikan Ilmu Pengetahuan dan/ atau Teknologi yang dikuasainya kepada mahasiswa dengan mewujudkan suasana belajar dan pembelajaran sehingga mahasiswa aktif mengembangkan potensinya. Adapun ayat 2 (dua) berbunyi Dosen sebagai ilmuwan memiliki tugas mengembangkan suatu cabang Ilmu Pengetahuan dan/atau Teknologi melalui penalaran dan penelitian ilmiah serta menyebarluaskannya. Dan pada ayat 3 (tiga) dusebutkan bahwa Dosen secara perseorangan atau berkelompok wajib menulis buku ajar atau buku teks, yang diterbitkan oleh Perguruan Tinggi dan/atau publikasi ilmiah sebagai salah satu sumber belajar dan untuk pengembangan budaya akademik serta pembudayaan kegiatan baca tulis bagi Sivitas Akademika. Oleh karena itu masalah penelitian ini dirumuskan sebagai berikut :

1. Bagaimana pengaruh persepsi kerja terhadap kinerja Dosen Sekolah Tinggi Pariwisata AMPTA Yogyakarta?

2. Bagaimana pengaruh motivasi kerja terhadap kinerja Dosen Sekolah Tinggi Pariwisata AMPTA Yogyakarta?

3. Bagaimana pengaruh kompensasi kerja terhadap kinerja Dosen Sekolah Tinggi Pariwisata AMPTA Yogyakarta?

4. Apakah kompensasi kerja memoderasi pengaruh persepsi kerja terhadap kinerja Dosen Sekolah Tinggi Pariwisata AMPTA Yogyakarta?

5. Apakah kompensasi kerja memoderasi pengaruh motivasi kerja terhadap kinerja Dosen Sekolah Tinggi Pariwisata AMPTA Yogyakarta?

Upaya menjelaskan pengaruh persepsi kerja dan motivasi kerja terhadap kinerja Dosen dan Tenaga Kependidikan Sekolah Tinggi Pariwisata AMPTA Yogyakarta dengan kompensasi kerja sebagai variabel moderasi dirincikan sebagai berikut :

1. Menganalisis dan menjelaskan pengaruh persepsi kerja terhadap kinerja Dosen dan Tenaga Kependidikan Sekolah Tinggi
Pariwisata AMPTA Yogyakarta;

2. 2Menganalisis dan menjelaskan pengaruh motivasi kerja terhadap kinerja Dosen dan Tenaga Kependidikan Sekolah Tinggi Pariwisata AMPTA Yogyakarta;

3. Menganalisis dan menjelaskan pengaruh kompensasi kerja terhadap kinerja Dosen dan Tenaga Kependidikan Sekolah Tinggi Pariwisata AMPTA Yogyakarta.

4. Menganalisis dan menjelaskankompensasi kerja memoderasi pengaruh persepsi kerja terhadap kinerja Dosen Sekolah Tinggi Pariwisata AMPTA Yogyakarta.

5. Menganalisis dan menjelaskankompensasi kerja memoderasi pengaruh motivasi kerja terhadap kinerja Dosen Sekolah Tinggi Pariwisata AMPTA Yogyakarta.

Hasil riset ini diharapkan dapat mengembangkan ilmu pengetahuan, baik konsep maupun teori, yang berkaitan dengan variabel-variabel yang digunakan dalam penelitian ini yang meliputi persepsi kerja, motivasi kerja dan kompensasi kerja dan kinerja dosen dan tenaga kependidikan. Selain itu juga untuk memberikan sumbangan pikiran mengenai pengembangan sumber daya manusia dalam bidang pendidikan pariwisata, yang berkaitan dengan kemampuan para dosen dan tenaga kependidikan, kususnya untuk meningkatkan kinerja dosen Sekolah Tinggi Pariwisata AMPTA Yogyakarta dalam melaksanakan tugasnya, memberikan bahan masukan dan evaluasi guna pengambilan kebijakan manajemen Sekolah Tinggi Pariwisata AMPTA Yogyakarta dan memberikan masukan kepada dosen Sekolah Tinggi Pariwisata AMPTA Yogyakarta agar meningkatkan kinerjanya.

\section{LANDASAN TEORI}

Kinerja seorang dosen, ditentukan oleh beberapa faktor. Diantaranya ditentukan oleh kompensasi kerja. Dengan pemberian kompensasi kerja yang baik, maka kinerja dosen akan optimal. Selain itu kinerja 
dosen juga ditentukan oleh persepsi dosen terhadap kerja yang dilakukan. Persepsi kerja yang merupakan hasil penginderaan seseorang dengan panca inderanya terhadap keadaan lingkungan sekitar yang akan memberi nyaman seseorang untuk bekerja Hal lain yang juga mempengaruhi kinerja dosen adalah motivasi kerja. Motivasi kerja merupakan keadaan kejiwaan dan sikap mental manusia yang memberi tenaga, mengarahkan, menyalurkan, mempertahankan, dan melanjutkan tindakan dan perilaku dosen. Motivasi dapat diartikan sebagai bagian integral dari hubungan industrial dalam rangka proses pembinaan, pengembangan, dan pengarahan sumber daya manusia dalam suatu perusahaan. Dengan demikian ketiga variabel tersebut tentunya akan mempengaruhi kinerja dosen. Oleh karena itu konsep teoritis ini akan diuji secara empiris dirumuskan sebagai berikut :

1. Diduga bahwa Persepsi Kerja memberikan pengaruh positif dan signifikan terhadap Kinerja Dosen Sekolah Tinggi Pariwisata AMPTA Yogyakarta;

2. DidugabahwaMotivasi Kerja memberikan pengaruh positif dan signifikan terhadap Kinerja Dosen Sekolah Tinggi Pariwisata AMPTA Yogyakarta

3. Diduga bahwa Kompensasi Kerja memberikan pengaruh positif dan signifikan terhadap KinerjaDosen Sekolah Tinggi Pariwisat AMPTA Yogyakarta.

4. Diduga kompensasi kerja memoderasi pengaruh persepsi kerja terhadap Kinerja Dosen Sekolah Tinggi Pariwisata AMPTA Yogyakarta .

5. Diduga kompensasi kerja memoderasi pengaruh motivasi kerja terhadap Kinerja Dosen Sekolah Tinggi Pariwisata AMPTA Yogyakarta.

\section{METODE PENELITIAN}

Penulis menggunakan metode inferensial dengan analisis kuantitatif. Penelitian ini idak melakukan treatment atau perlakuan khusus. Melainkan meneliti masalah atau peristiwa yang telah terjadi dan tidak melakukan kontrol terhadap variabel penelitian, Melainkan melihat variabel sebagaimana adanya. Sehingga penelitian ini menggunakan pendekatan ex post facto, Menurut Nasir (2009) bahwa metode ex post facto maksudnya adalah penelitian empiris sistematis ini tanpa melakukan perlakuan- perlakuan maupun manipulasi terhadap variabel penelitian. Tetapi hanya mengumpulkan fakta-fakta berdasarkan pengukuran terhadap gejala yang terjadi pada diri responden sebelumnya.
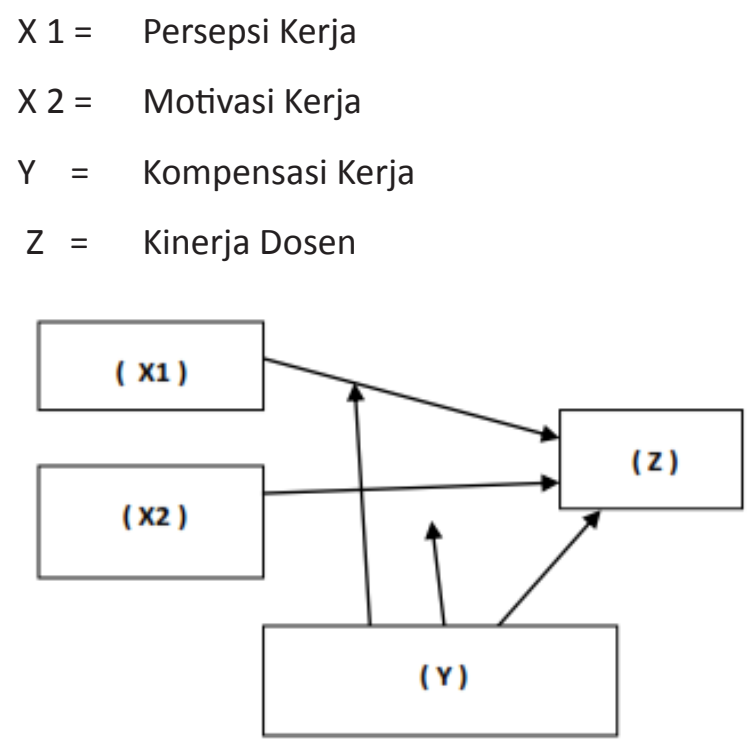

Gambar 1. Desain Penelitian

Penelitian ini menggunakan pendekatan kuantitatif karena data-data penelitian ini berupa angka-angka. Sementara itu penelitian ini mempergunakan metode deskriptif, karena kegiatannya meliputi pengumpulan data dalam rangka menguji hipotesis. Metode penelitian ini juga disebut penelitian korelasi karena peneliti ingin tingkat hubungan variabel-variabel yang berbeda dalam suatu populasi.

Penelitian ini mempergunakan desain penelitian regresi linier berganda yang didasarkan pada hubungan fungsional 2 variable, yaitu variable independent dan variable dependent. Di bawah ini gambaran desain penelitian sebagai berikut (gambar $1)$. 
Penelitian yang dilakukan peneliti mengambil lokasi di Sekolah Tinggi Pariwisata AMPTA Yogyakarta yang beralama di Jalan Adisucipto Km. 6 Tempel, Caturtunggal Depok, Sleman, Yogyakarta 55281, yang dilaksanakan selama 4 (empat) bulan, dari bulan Juni2015 sampai dengan September 2015 terhadap 39 dosen. Data dikumpulkan dengan menggunakan kuesioner (setelah memenuhi uji kelayakan instrument), wawancara dan dokumentasi, yang kemudian di analisis dengan model persamaan regresi brganda

\section{HASIL PENELITIAN PEMBAHASAN}

Persamaan regresi linier berganda digunakan untuk mengetahui pengaruh variabel bebas antara lain: persepsi kerja dan motivasi kerja terhadap Kinerja Dosen dengan Kompensasi Kerja sebagai variabel moderasi, dimana output pada SPSS for Window Versi 16.0 ditunjukkan pada tabel 1.

Dilihat dari tabel tersebut diatas, diperolah persamaan garis linier berganda ( yang dilihat dari koefisien standar atau standardized coefficient didapatkan :

$$
\begin{aligned}
Y=\quad & 9,546+0,782 X 1+2,294 X 2+1,578 \\
& Z+0,145 X 1 Z+0,572 X 2 Z .
\end{aligned}
$$

\begin{tabular}{|c|c|c|c|c|c|}
\hline \multirow{2}{*}{ Model } & \multicolumn{2}{|c|}{$\begin{array}{l}\text { Unstandardized } \\
\text { Coefficients }\end{array}$} & $\begin{array}{l}\text { Standardized } \\
\text { Coefficients }\end{array}$ & \multirow{2}{*}{$\mathrm{t}$} & \multirow{2}{*}{ Sig. } \\
\hline & $\mathrm{B}$ & Std. Error & Beta & & \\
\hline Constant & 9,546 & 10,015 & & ,953 &, 347 \\
\hline PersepsiKerjaX1 & ,782 & ,709 & ,673 & 3,103 &, 008 \\
\hline MotivasiKerjaX2 & 2,294 & 2,070 & 1,927 & 4,108 &, 002 \\
\hline KinerjaDosenZ & 1,578 & 2,342 & 1,526 & 2,674 &, 025 \\
\hline $\mathrm{X} 1 \mathrm{Z}$ & ,145 & , 163 & ,970 & 2,895 &, 017 \\
\hline $\mathrm{X} 2 \mathrm{Z}$ &, 572 &, 480 & 4,379 & 2,191 &, 034 \\
\hline$F=18,078$ & \multicolumn{2}{|c|}{ Sig., $000^{b}$} & \multicolumn{3}{|c|}{ R Square $=0.640$} \\
\hline
\end{tabular}

Keterangan : Tabel 1. Koefficien Regersi Berganda

a.Dependent Variabel TY

$\mathrm{Y} \quad=$ variabel Kompensasi Kerja

$\mathrm{B} 1-\mathrm{b} 5=$ koefisien regresi

$\mathrm{X} 1=$ variabel Persepsi Kerja

$\mathrm{X} 2=$ variabel Motivasi kerja

Koefisien standar (standardized coefficients) pada persamaan diatas digunakan untuk mengetahui besarnya kontribusi $\mathrm{m}$ asing- masing faktor yang berpengaruh terhadap Kompensasi Kerja. Dari persamaan tersebut faktor utama yang paling berpengaruh terhadap kompensasi kerja yaitu faktor motivasi kerja karena memiliki koefisien regresi terbesar yaitu
$\mathrm{Z} \quad=$ variabel Kinerja Dosen

$\mathrm{X} 1 \mathrm{Z}=$ interaksi persepsi kerja dan kinerja dosen

$\mathrm{X} 2 \mathrm{Z}=$ interaksi motivasi kerja dengan kinerja dosen.

2.294, selanjutnya faktor kinerja dosen dengan angka koefisien regresi sebesar 1,578 , faktor perspsi kerja dengan angka koefisien regresi sebesar 0,782, faktor interaksi motivasi kerja dengan kinerja dosen dengan angka koefisien regresi sebesar 0,572 dan interaksi persepsi kerja dengan kinerja dosen dengan angka koefisien regresi sebesar 0,145 . 


\section{Uji F}

Dari tabel1 diatas menunjukkan bahwa nilai signifikasi $\mathrm{F}$ sebesar 0,000 lebih kecil dibandingkan taraf signifikan $5 \%$ atau $(0,05)$ sehingga dapat disimpulkan bahwa Persepsi Kerja (X1), Motivasi Kerja (X2), Kinerja Dosen (Z) dan interaksi Persepsi Kerja dengan Kinerja Dosen (X1Z) dan interaksi Motivasi Kerja dengan Kinerja Dosen (X2Z) secara bersama-sama berpengaruh signifikan dan positif terhadap Kompensasi Kerja (Y). Hal ini menunjukkan bahwa model yang diajukan layak untuk diteruskan.

\section{Koefisien Determinasi (R Square)}

Dari hasil uji regresi didapatkan angka koefisien determinasi (Adjusted $R$ Square) sebesar 0,640 Hal ini berarti bahwa variabel Persepsi Kerja (X1), Motivasi Kerja (X2), Kinerja Dosen (Z), Persepsi Kerja dengan Kinerja Dosen (X1Z) dan interaksi Motivasi Kerja dengan Kinerja Dosen (X2Z) terhadap Konpensasi Kerja (Y) memiliki konstribusi sebesar $64,0 \%$. Sedangkan faktor lain yang berpengaruh terhadap Kompensasi Kerja memiliki konstribusi sebesar ( $100 \%$ $-64,0 \%)=36,0 \%$. Hal ini berarti bahwa model yang diajukan layak untuk diteruskan.

\section{Uji Hipotesis}

\section{Pengaruh \\ Persepsi terhadapKompensasi Kerja}

Kerja

Berdasarkan pengujian statistik dengan SPSS for Windows Versi 16.0 didapat angka signifikanasi Persepsi Kerja (X1) terhadap Kompensasi Kerja (Y) sebesar 0,008 $\leq$ taraf signifikansi $\alpha=5 \%(0,05)$; berarti secara parsial (individu) teredapat pengaruh yang positif dan signifikan Persepsi Kerja (X1) terhadap Kompensasi Kerja (Y).

\section{Pengaruh Motivasi Kerja terhadap Kompensasi Kerja}

Berdasar pengujian statistik dengan SPSS for Windows Versi 16.0 diperoleh angka signiofikasi Motivasi Kerja (X2) terhadap Kompensasi Kerja (Y) sebesar $0,002 \leq$ taraf signifikansi $\alpha=5 \%(0,05)$; berarti secara parsial (individu) terdapat pengaruh yang positif dan signifikan antara Motivasi Kerja (X2) terhapap Kompensasi Kerja (Y)

\section{Pengaruh Kinerja Dosen terhadap Kompensasi Kerja}

Berdasar pengujian statistik dengan SPSS for Windows Versi 16.0 diperoleh angka signifikansi Kinerja Dosen (Z) terhadap Kompensasi Kerja (Y) sebesar $0,025 \leq$ taraf signifikansi $\alpha=55$ 90,05); berarti secara parsial (individu) terdapat pengaruh yang positif dan signifikan antara Kinerja Dosen ( $\mathrm{Z}$ ) terhadap Kompensasi Kerja (Y)

\section{Pengaruh Interaksi Persepsi Kerja dengan Kinerja Dosen terhadap Kinerja Dosen}

Berdasarkan pengujian statistik dengan SPSS for Windows Versi 16.0 diperoleh angka signifikansi interaksi Persepsi Kerja dengan Kinerja Dosen (X1Z) terhadap Kinerja Dosen (Z), yang semula TX1 0,008 menjadi TX1Z 0,017 setelah ada Kinerja Dosen (Z), pengaruh Persepsi Kerja (X1) terhadap Kompensasi Kerja (Y) menjadi lebih besar, artinya Persepsi Kerja dan Kinerja Dosen memnoderasi terhadap Kinerja Dosen (Z).

\section{Pengaruh interaksi Motivasi Kerja dengan Kinerja Dosen terhadap Kinerja Dosen.}

Dersasar pengujian statistik dengan SPSS for Windows Versi 16.0 didapatkan angka signifikansi interaksi Motivasi Kerja dengan Kinerja Dosen (X2Z) terhadap Kinerja Dosen (Z), yang semula TX2 0,002 menjadi TX2Z 0,034 setelah ada Kinerja Dosen $(Z)$ pengaruh Motivasi Kerja (X2) terhadap Kompensasi Keerja (Y) 
menjadi lebih besar, artinya motivasi kerja dan Kinerja Dosen memoderasi terhadap Kompensasi Kerja.

Hasil penelitian ini menunjukkan bahwa persepsi kerja, motivasi kerja, kompensasi kerja dan variable mode $r$ asi secara bersama-sama memberikan kontribusi terhadap peningkatan kinerja dosen. Angka-angka sumbangan efektif variabel bebas terhadap nilai variabel terikat tersebut adalah merupakan hasil analisis data lapangan yang rnerefleksikan tingkat keefektifan pelaksanaan persepsi kerja, motivasi kerja, kompensasi kerja, sehagai variabel independen terhadap Kinerja dosen Sekolah Tinggi Pariwisata "AMPTA" Yogyakarta. Temuan penelitian ini mengungkapkan bahwa persepsi kerja, motivasi kerja, dan kompensasi kerja memiliki nilai jalur hubungan kausal yang signifikan antara satu dengan lainnya terhadap kinerja dosen.

\section{Pengaruh Persepsi Kerja Terhadap Kinerja Dosen}

Hasil penelitian ini rnenunjukkan bahwa ada pengaruh positif dan signifikan antara persepsi kerja terhadap kinerja dosen Sekolah Tinggi Pariwisata "AMPTA" Yogyakarta. Artinya dalarn penelitian ini, persepsi kerja berpengaruh positif, sehingga kinerja dosen Sekolah Tinggi Pariwisata "AMPTA" Yogyakarta sernakin meningkat. Hasil penelitian yang mendukung rnengenai pengaruh persepsi kerja terhadap kinerja dosen Sekolah Tinggi Pariwisata “AMPTA”Yogyakarta, telah dilakukan oleh beberapa peneliti antara lain Made Krisna Andi Putra, Iyus Akhmad Haris,Made Ary Meitriana, 2014 hasil penelitian menunjukkan Persepsi guru tentang gaya kepemimpinan kepala sekolah berpengaruh signifikan terhadap kinerja guru SMK N 1 Gianyar tahun pelajaran 2013/2014.

\section{Pengaruh Motivasi Kerja Terhadap Kinerja Dosen}

Hasil penelitian menunjukkan bahwa ada pengaruh yang positif dan signifikan antara motivasi kerja terhadap kinerja dosen, artinya dalam penelitian ini. motivasi kerja akan berpengaruh positif, sehingga kinerja dosen semakin baik atau meningkat. Penelitian ini mendukung penelitian terdahalu rnengenai pengaruh motivasi kerja terhadap ki nerja yaitu Dhermawan, Sudibya, Utama, (2012) menunjukkan bahwa motivasi, kondisi lingkungan kerja, kompetensi dan kompensasi pegawai yang perlu ditingkatkan guna meningkatkan kepuasan kerja dan apabila kepuasan kerja pegawai meningkat maka kinerja pegawai juga akan meningkat.

\section{Pengaruh Kompensasi Kerja Terhadap Kinerja Dosen}

Terbukti kompensasi kerja berpengaruh positif dan signifikan terhadap kinerja dosen Sekolah Tinggi Pariwisata "AMPTA" Yogyakarta. Artinya kompensasi kerja mempunyai pengaruh terhadap kinerja dosen. Hasil penclitian ini mendukung penelitian terdahulu yaitu yang dilakukan Karnelis, (2011) menunjukkan bahwa Kompensasi dan Kepuasan kerja secara bersama-sama berpengaruh signifikan terhadap kinerja mengajar dosen pada Sekolah Tinggi Ilmu Manajemen Pase Langsa dan secara parsial kompensasi berpengaruh lebih dominan daripada kepuasan kerja. Secara simultan kompensasi dan kepuasan kerja berpengaruh signifikan terhadap kinerja mengajar dosen. Menurut peneliti, apabila pimpinan melakukan perbaikan kompensasi secara proporsional, maka hal tersebut akan meningkatkan kinerja dosen Sekolah Tinggi Pariwisata "AMPTA" Yogyakarta. Kenyataan dilapangan, STP AMPTA Yogyakarta melalui persetujuan Yayasan telah memberikan Perumahan sebagai kompensasi terhadap para Dosen perintis 
yang telah bekerja sejak STP AMPTA berdiri tahun 1987.

\section{Pengaruh Persepsi Kerja terhadap Kinerja Dosen Dengan Kompensasi Kerja sebagai Variabel Moderasi.}

Efek moderasi dari kompensasi kerja dalam hubungannya dengan persepsikerja dalampenelitianiniternyata berpengaruh positif dan signifikan terhadap kinerja dosen di Sekolah Tinggi Pariwisata "AMPTA" Yogyakarta. Efek moderasi kompensasi kerja ternyata memperkuat terhadap kinerja dosen. Penelitian ini mendukung penelitian terdahulu yang dilakukan oleh Made Krisna Andi Putra, Ilyus Akhmad Haris, Made Ary Meitriana dari Jurusan Pendidikan Ekonomi Universitas Pendidikan Ganesha, Singaraja yang ingin mengetahui pengaruh Persepsi guru tentang gaya kepemimpinan Kepala Sekolah terhadap kinerja guru. Di STP AMPTA Yogyakarta, disamping atasan telah memberikan pengawasan juga membantu meningkatkan prestasi kerja tiap dosen termasuk mengingatkan kepada dosen yang belum lengkap persyaratannya dalam mengikuti program Sertifikasi Dosen.

\section{Pengaruh Motivasi Kerja terhadap Kinerja Dosen Dengan Kompensasi Kerja sebagai Variabel Moderasi.}

Efek moderasi dari kompensasi kerja dalam hubungannya dengan motivasi kerja dalam penelitian ini ternyata berpengaruh positif dan signifikan terhadap kinerja dosen Sekolah Tinggi Pariwisata AMPTA Yogyakarta. Efek moderasi motivasi kerja ternyata memperkuat terhadap kinerja dosen. Hal ini sesuai dengan hasil penelitian terdahulu yang telah dilakukan oleh Sri Wulandari 2012 dari Institut Agama Islam Negeri (IAIN) Walisongo.

\section{KESIMPULAN}

Berdasarkan hasil analisis data dan pembahasan sebelumnya, maka dapat disimpulkan rumusan masalah sebagai berikut :

1. Persepsi kerja berpengaruh positif dan signifikan terhadap Kinerja Dosen Sekolah Tinggi Pariwisata AMPTA Yogyakarta. Semakin tinggi penilaian Persepsi Kerja, maka semakin tinggi kinerja dosen.

2. Motivasi Kerja berpengaruh positif dan signifikan terhadap Kinerja Dosen

3. Sekolah Tinggi Pariwisata AMPTA Yogyakarta. Artinya semakin besar motivasi yang diberikan kepada dosen, maka semakin baik Kinerja Dosen.

4. 3.Kompensasi Kerja berpengaruh positif dan signifikan terhadap Kinerja Dosen. Berarti semakin besar Kompensasi Kerja yang diberikan, maka semakin baik Kinerja Dosen.

5. Kompensasi Kerja memoderasi pengaruh Persepsi Kerja terhadap Kinerja Dosen. Artinya dengan Kompensasi Kerja yang semakin besar akan memperkuat pengaruh Persepsi Kerja (X1) terhadap Kinerja Dosen.

6. Kompensasi Kerja memoderasi pengaruh Motivasi Kerja terhadap Kinerja Dosen Sekolah Tinggi Pariwisata AMPTA Yogyakarta. Artinya dengan Kompensasi Kerja yang baik, maka semakin baik Kinerja Dosen dan Motivasi Kerja semakin kuat mempengaruhi Kinerja Dosen.

Berdasarkan temuan penelitian ini maka, secara manajerial perlu mempertimbangkan hal-hal berikut ini:

1. Persepsi Kerja merupakan hasil pengindraan seseorang terhadap keadaan lingkungan sekitar yang akan memberikan kenyamana seseorang untukbekerja. Persepsi kerja pada jawaban yang paling rendah adalah pernyataan nomor 5 yaitu atasan membantu meningkatkan prestasi kerja 
dosen. Bila para dosen di Sekolah Tinggi Pariwisata AMPTA Yogyakarta merasa dibantu dalam meningkatkan prestasinya, maka gairah kerja menjadi optimal, disarankan kepada pimpinan/ Ketua Jurusan untuk memberikan bantuan dalam peningkatan prestasi kerja dosen, dan memberikan penghargaan bagi dosen yang berprestasi dalam proses belajar mengajar atau dalam pelaksanaan Tri Dharma Perguruan Tinggi yang lain.

2. Motivasi Kerja adalah kondisi yang membuat para dosen mempunyai kemauan untuk mencapai tujuan tertentu melalui pelaksanaan tugas. Pada pernyataan yang paling rendah adalah kebutuhan adanya kesepakatan dosen lainnya atau peka terhadap pengaruh orang lain. Disarankan kepada Ketua Sekolah Tinggi Pariwisata AMPTA Yogyakarta atau Ketua Jurusan untuk membina hubungan antar dosen agar terjalin hubungan baik yang saling menguntungkan satu sama lain .

3. Kinerja Dosen. Sudarmanto (2014) istilah kinerja menunjuk pada pengertian sebagai hasil/produktivitas, juga merupakan seperangkat perilaku yang relevan dengan tujuan organisasi tempat orang bekerja. Pada pernyataan yang paling rendah pada kinerja dosen pernyataan nomor 41 yaitu menjadi panitia seminar . Disarankan kepada Ketua Sekolah Tinggi Pariwisata AMPTA Yogyakarta atau Ketua Jurusan untuk memberikan insentif bagi para dosenyang bersedia melaksanakan seminar atau menjadi panitia dalam penyelenggaraan suatu seminar ilmiah.

4. Kompensasi Kerja. Kompensasi adalah keseluruhan dari semua hadiah yang diberikan kepada karyawan sebagai imbalan atas jasa mereka (Mondy \& Noe 2005). Pada pernyataan yang paling rendah dalam Kompensasi Kerja adalah besaran tunjangan yang memadai. Maka disarankan kepada Ketua Sekolah Tinggi Pariwisata AMPTA Yogyakarta untuk memberikan besaran tunjangan yang memadai kepada dosen sesuai dengan kemampuan keuangan Lembaga, agar gairah kerja para dosen dapat meningkat.

Implikasi penting dari hasil penelitian, (1) untuk meningkatkan Kinerja Dosen harus memperhatikan faktor-faktor yang dapat meningkatkan Kinerja Dosen yaitu Persepsi Kerja, Motivasi Kerja dan Kompensasi Kerja. Persepsi Kerja dan Motivasi Kerja dengan dimodersai oleh Kompensasi Kerja memiliki pengaruh positif dan signifikan terhadap Kinerja Dosen Sekolah Tinggi Pariwisata AMPTA Yogyakarta, maka ketiga-tiganya harus ditingkatkan (2) berdasarkan analisis jalur bahwa Kinerja Dosen di Sekolah Tinggi Pariwisata AMPTA Yogyakarta dipengaruhi langsung oleh Persepsi Kerja, Motivasi Kerja dan Kompensasi Kerja, sehingga untuk meningkatkan Kinerja Dosen harus memperhatikan ketiga variabel tersebut. Artinya untuk meningkatkan Kinerja Dosen dapat langsung meningkatkan Persepsi Kerja, Motivasi Kerja dan Kompensasi Kerja.

Keterbatasan Penelitian ini berkaitan dengan (1) variabel yang mempengaruhi Kinerja hanya membahas 3 variabel bebas yaitu Persepsi Kerja, Motivasi Kerja dan Kompensasi Kerja (2) penelitian dilakukan hanya di Sekolah Tinggi Pariwisata AMPTA Yogyakarta, dan (3) jawaban responden yang cenderung sama, oleh karena itu riset yang akan datang sebaiknya (1) dilakukan pada obyek penelitian yang lebih luas dan obyek yang berbeda. Hal ini untuk mengetahui apakah variabel dan metode yang digunakan juga dapat berlaku untuk obyek penelitian yang berbeda (2) memasukkan variabel lain misalnya pengembangan karier dosen.

\section{DAFTAR PUSTAKA}


Adler and Rodman (2009), Understanding human communication $\left(10^{\text {th }}\right.$ ed.). New York: Oxford University Press.

Arikunto, Suharsimi, 2010, Prosedur Penelitian Suatu Pendekatan Praktik, Edisi Keempat belas. Jakarta: PT. Rineka Cipta.

Danuji, Sahid dan Rahadhini, 2012, Efek Moderasi Kompensasi Pada Pengaruh Motivasi Dan Kepuasan Kerja Terhadap Kinerja Karyawan, Jurnal Manajemen Sumber daya Manusia 6 (2) : $115-128$ Departemen Pendidikan Nasional, 2012, Undang-undang Nomor 12 Tahun 2012 Tentang Pendidikan Tinggi, Jakarta: Depdiknas.

Departemen Pendidikan Nasional, 2014, Peraturan Pemerintah No 4 Tahun 2014 Tentang Penyelenggaraan Pendidikan Tinggi dan Pengelolaan Perguruan Tinggi , Jakarta: Depdiknas.

Dhermawan, Sudibya, Utama, 2012, Pengaruh Motivasi, Lingkungan Kerja, Kompetensi dan Kompensasi terhadap Kepuasan Kerja dan Kinerjapegawai di Lingkungan Kantor Dinas Pekerjaan Umum Provinsi Bali . Fakultas Ekonomi Universitas Udayana.

Dirjen Dikti Kementerian Pendidikan dan Kebudayaan, 2013, Buku Pedoman Sertifikasi Pendidik Untuk Dosen (Serdos) Terintegrasi, Buku 2 Penilaian Porto Folio.

Dwiloka, Bambang, dan Riana, Rati, 2012, Teknik Menulis Karya Ilmiah. Edisi Kedua. Jakarta: PT. Rineka Cipta.

Fahmi, Irham, 2014, Perilaku Organisasi, Teori, Aplikasi dan Kasus. Cetakan Kedua, Bandung : Alfabeta.

Handoko, Hani 2014, Manajemen Sumber Daya Manusia .Edisi Kedua, Yogyakarta : BPFE.
Hasibuan, Malayu SP, 2014, Organisasi dan Motivasi. Cetakan Kedelapan. Jakarta : PT. Bumi Aksara.

Karnelis, 2011, Pengaruh Kompensasi dan Kepuasan Kerja Terhadap Kinerja Mengajar Dosen di Sekolah Tinggi Ilmu Manajemen Pase Langsa

Miftah Thoha, 2014, Perilaku Organisasi, Konsep Dasar dan Aplikasi. Cetakan ke 22 . Jakarta : Raja Grafindo Persada.

Oei, Istijanto. 2010. Riset Sumber Daya Manusia, Cetakan Keempat. Jakarta: PT. Gramedia.

Peraturan Pemerintah Republik Indonesia No.17 tahun 2010 tentang Pengelolaan dan Penyelenggaraan Pendidikan.

Putra Made Krisna Andi, Iyus Akhmad Haris,Made Ary Meitriana, 2014, Pengaruh Persepsi Guru Tentang Gaya Kepemimpinan Kepala Sekolah Dan Iklim Kerja Terhadap Kinerja Guru, Bali, Universitas Pendidikan Ganesha.

Sedarmiyanti, 2009, Sumberdaya Manusia dan Produktivitas Kerja. Cetakan Ketiga, Bandung : Mandar Maju.

Sugiyono, 2011, Metode Penelitian Kuantitatif, Kualitatif dan $R \& D$. Cetakan Keempatbelas, Bandung : Alfabeta, cv.

Sugiyono, 2014, Statistika Untuk Penelitian. Cetakan ke dua puluh empat. Bandung: Alfabeta,cv.

Sutrisno, Edy. 2010. Manajemen Sumber Daya Manusia. Edisi Kedua. Jakarta: Kencana Perdana Media Group.

Undang-undang Republik Indonesia No 12 Tahun 2012 Tentang Pendidikan Tinggi.

Yuses Alkadira Mitas, 2013, Peranan Kompensasi sebagai Variabel 
Moderasi dalam Pengaruh Motivasi Kerja, Kepuasan Kerja dan Gaya Kepemimpinan terhadap Kinerja Pegawai (Studi Pada Dinas Kesehatan Kabupaten Kerinci), Tesis, Sumatera Utara, Universitas Bung Hata.

Wibowo, 2014. Manajemen Kinerja. Edisi Keempat, Jakarta PT Raja Grafindo Persada . 